University of Texas Rio Grande Valley

ScholarWorks @ UTRGV

Manufacturing \& Industrial Engineering Faculty

Publications and Presentations

College of Engineering and Computer Science

$6-22-2020$

\title{
Embedding Computer Simulation Based Classroom Activities to Enhance the Learning Experience for Manufacturing Systems
}

\author{
Tzu-Liang Bill Tseng \\ University of Texas at El Paso \\ Md Fashiar Rahman \\ University of Texas at El Paso \\ Richard Chiou \\ Ivan Arturo Renteria-Marquez \\ Aditya Akundi \\ The University of Texas Rio Grande Valley
}

See next page for additional authors

Follow this and additional works at: https://scholarworks.utrgv.edu/mie_fac

Part of the Education Commons, Industrial Engineering Commons, and the Manufacturing Commons

\section{Recommended Citation}

Tseng, T. B., \& Rahman, M. F., \& Chiou, R., \& Renteria-Marquez, I. A., \& Akundi, A., \& Lopes, A. J., \& Senthilkumar, J. (2020, June), Embedding Computer Simulation-based Classroom Activities to Enhance the Learning Experience for Manufacturing Systems Paper presented at 2020 ASEE Virtual Annual Conference Content Access, Virtual On line . 10.18260/1-2--34519

This Conference Proceeding is brought to you for free and open access by the College of Engineering and Computer Science at ScholarWorks @ UTRGV. It has been accepted for inclusion in Manufacturing \& Industrial Engineering Faculty Publications and Presentations by an authorized administrator of ScholarWorks @ UTRGV. For more information, please contact justin.white@utrgv.edu,william.flores01@utrgv.edu. 


\section{Authors}

Tzu-Liang Bill Tseng, Md Fashiar Rahman, Richard Chiou, Ivan Arturo Renteria-Marquez, Aditya Akundi, Amit J. Lopes, and Jeevarathinam Senthilkumar 


\section{Embedding Computer Simulation Based Classroom Activities to Enhance the Learning Experience for Manufacturing Systems}

\section{Prof. Tzu-Liang Bill Tseng, University of Texas at El Paso}

Dr. Tseng is a Professor and Chair of Industrial, Manufacturing and Systems Engineering at UTEP. His research focuses on the computational intelligence, data mining, bio- informatics and advanced manufacturing. Dr. Tseng published in many refereed journals such as IEEE Transactions, IIE Transaction, Journal of Manufacturing Systems and others. He has been serving as a principle investigator of many research projects, funded by NSF, NASA, DoEd, KSEF and LMC. He is currently serving as an editor of Journal of Computer Standards \& Interfaces.

\section{Mr. Md Fashiar Rahman, University of Texas at El Paso}

Md Fashiar Rahman is currently a doctoral student at the University of Texas at El Paso in Computational Science Program. He earned Master of Science in Computational Science at the University of Texas at El Paso (UTEP) in 2018. He has worked on a number of projects in the field of image data mining, machine learning and deep learning for industrial inspection and quality control. His research interests are in big data analytics, application of machine learning and deep learning for digital quality control. Email:mrahman13@miners.utep.edu

\section{Dr. Richard Chiou, Drexel University}

Dr. Richard Chiou is Associate Professor within the Engineering Technology Department at Drexel University, Philadelphia, USA. He received his Ph.D. degree in the G.W. Woodruff School of Mechanical Engineering at Georgia Institute of Technology. His educational background is in manufacturing with an emphasis on mechatronics. In addition to his many years of industrial experience, he has taught many different engineering and technology courses at undergraduate and graduate levels. His tremendous research experience in manufacturing includes environmentally conscious manufacturing, Internet based robotics, and Web based quality. In the past years, he has been involved in sustainable manufacturing for maximizing energy and material recovery while minimizing environmental impact.

Dr. Ivan Arturo Renteria-Marquez, University of Texas at El Paso. Industrial, Manufacturing \& Systems Engineering Department

Ivan Arturo Renteria Marquez was born in Ciudad Juárez, Chihuahua. In the spring of 2005 he entered the Mechatronic engineering program at Tecnológico de Monterrey with an academic scholarship. In the spring of 2011 he graduated with distinction. In the spring of 2012 he entered the PhD fast track program in Electrical and Computer Engineering offered at the University of Texas at El Paso. In the spring of 2016 he obtained his Philosophy Degree with specialty in Electrical engineering. He currently works as Research Assistant Professor in the Industrial Manufacturing \& Systems Engineering Department at University of Texas at El Paso.

\section{Dr. Aditya Akundi, The University of Texas Rio Grande Valley}

Aditya Akundi is currently affiliated to the Manufacturing and Industrial Engineering Department, at the University of Texas Rio Grande Valley. He earned a Bachelor of Technology in Electronics and Communication Engineering from Jawaharlal Nehru Technological University, India. He earned a Master of Science in Electrical and Computer Engineering at the University of Texas at El Paso (UTEP). and a Ph.D. in Electrical and Computer Engineering, with a concentration in Industrial and Systems Engineering (ISE) in 2016. His research is focused on understanding Complex Technical and Socio-Technical Systems from an Information Theoretic approach. He has worked on a number of projects in the field of Electrical \& Computer Engineering, Systems Engineering, Additive Manufacturing and Green Energy Manufacturing. His research interests are in Systems Engineering \& Architecture, Complex systems, Systems testing and Application of Entropy to Complex Systems. 


\section{Dr. Amit J Lopes, UTEP}

Dr. Lopes' research interests focus on additive manufacturing and its applications. His research also includes Service Systems Engineering applications to additive manufacturing, healthcare, and energy systems. He is also interested in the application of lean manufacturing principles to improve additive manufacturing processes and operations.

\section{Mr. Jeevarathinam Senthilkumar}




\title{
Embedding Computer Simulation Based Classroom Activities to Enhance the Learning Experience for Manufacturing Systems
}

\begin{abstract}
In recent time, manufacturing environment are bracing higher end technologies to achieve high productivity, efficiency and effectiveness. Due to the adoption of the sophisticated technologies, the system is becoming very complex and stochastic. Moreover, the manufacturing system is interconnected among its different subsystems and components, which cannot be described only through the theoretical explanation. Here, computer simulation can be integrated to design and visualize the stochastic and complex system. This paper uses the advantage of simulation to describe a series classroom activity using SIMIO software, which are deployed in industrial systems simulation course in the University of Texas at El Paso. Besides, the authors show a noble approach to demonstrate the simulation using the virtual reality (VR) technology in Unity platform. Integration of these simulation based classroom activities provide three-fold benefit to students' learning process; (1) it provides an effective way to evaluate the design and operational performance of manufacturing systems, (2) students can experience the real time situation by imitating a manufacturing environment, and (3) it motivates the students to be engaged in the classroom activities besides learning the theoretical knowledge.

Keywords: Computer simulation, virtual reality, manufacturing systems
\end{abstract}

\section{INTRODUCTION:}

The landscape of engineering education is changing continuously to address the complex societal challenges of the $21^{\text {st }}$ century [1] . Everyday new types of problems are emerging which involve new generation of machines, materials and systems. Especially, the area of manufacturing is getting more complex and stochastic resulting a lot of challenges for the engineering education. For example, the emergent of industrial 4.0 or smart factory comes with a very complicated information flow and man-machine system [2]. This necessitates to rethink the way of educating engineers for the future. Considering this fact, this paper investigates an approach of integrating the simulation-based activities in the classroom to bring changes in the learning outcomes of manufacturing course.

Over the last few decades, traditional manufacturing/production engineering educational programs have long depended on curricula based on concurrent engineering methodologies covering product and process designs, functional design development, concept selection for product design, materials and process selection, process planning including assembly analysis, etc., all aimed at optimally selected designs and manufacturing practices for economic manufacturing [3]. These programs however suffer from the lack of consideration of real-time environment and situation. The traditional classroom activity and course curricula are not sufficient to meet the challenges of this century. Hence institutions are continuously trying to provide better understanding to the learners by developing new curricula and infusing different methods in classroom activity. Attempts need to cover the entire production system and provide understanding of the total lifecycle effects of products, process and systems involved in manufacturing. Of course, there are scarcity of resources and time to create a real time manufacturing environment for the learning purpose. Creating a real time environment for classroom activity is also infeasible. Sometimes students are encouraged to do internship at different organization to get the idea of a real 
manufacturing plant. This may help to minimize the learning gap at a certain level. However, all the students of a course do not get the opportunity to do internship due to its competitive nature, restrictions and requirements. Here, the computer simulation-based classroom activity can play a critical role to attain the course objectives.

Manufacturing process/system can be defined as the steps, activities, tasks, stages and decision involving the development of a new product or improvements on an existing product. The computer simulation provides an effective visual method to aggregate of the aforementioned components of a manufacturing process. This enables the companies to model a system in a quick, effective and flexible way resulting cost reduction and better use of resources $[4,5]$. For example, within a production process, the assembly stage is responsible for a considerable percentage of time and resource allocation. So, computer simulation can be used for simulating the assembly line and explore the different possibilities with lower lead times and costs resulting more productivity. Thus, the use of computer simulation is getting more popularity in every aspect of a manufacturing system. Besides, in the last couple of year, companies showed their great interest in applying the virtual reality in many areas of manufacturing process [6]. Virtual reality in manufacturing is referred to as digital design, simulation and integration. It is comparable to a monitor on steroids, and users can interact with the digital simulation. It enables the users to explore and interact with the three-dimensional computer-generated environment [7,8]. That users become a part of this virtual environment to manipulate objects or perform a series of action. Essentially, this eliminates to build the complex prototype to review design, hastening the design-to-finished product time frame. Additionally, this improves the worker safety, creates better products, and saves money. The acceptance of this promising technology is remarkably growing most likely for cost reduction and allowing small and medium-sized manufacturers to take advantage of its power.

Considering the promising use of computer simulation and virtual reality, we incorporate these tools into Industrial Systems Simulation course curriculum. This course was offered in Fall 2019 semester from the Industrial, Manufacturing and System Engineering (IMSE) department at the University of Texas at El Paso. The course was offered for graduate program where 12 students were enrolled. We used the SIMIO software for computer simulation and unity platform to demonstrate the application of virtual reality. Different hand-on activities were included into the coursework and later tested with simulation modelling. A project has been accomplished using the virtual reality to show the human centric interaction of different components of a product. Finally, the learning outcomes has been accessed through students' report and quiz. The rest part of this paper contains the sections including the computer simulation using SIMIO, virtual reality model development, student assessment, and the conclusion.

\section{COMPUTER SIMULATION USING SIMIO:}

This section describes the projects which was accomplished to simulate the activities of different section of a manufacturing plant using a simulation software called SIMIO [9]. In this project, we used the Discrete event simulation (DES) method. This method is used to simulate the behavior and performance of a real-life process, facility or system [10]. It models the system as a series of 'events' that occurs over time. In a manufacturing environment, the subsystems/components are modelled as independent entities each of which can be given associated attributes information. In the case of manufacturing plant simulation this may include parameters such as inputs, controls, mechanism and output of the processes. The information may be modified as time runs in the 
simulation model, e.g, the location will be hanged depending in the status of the units in the network. The simulation model also considered the resources allocation.

The discrete event simulation project presented in this manuscript is a real case study of a trailer camper manufacturing assembly plant located in the USA. This manufacturing plant has a single flexible manufacturing line where four different product types are assembled. This manufacturing plant is divided into four main areas which are: chassis, deck, skeleton, panels, roof, final assembly, painting, and testing. Additionally, there is a subassembly area where the electrical components are assembled together. This simulation project is part on an effort to expand the operations of this company. The sales of this company are being increasing during the last years; motivated by this, the top management decided to invest in the design of a bigger facility with higher production capacity. The simulation model was created using SIMIO simulation software, the reason for choosing this software is because it offers four discrete modeling paradigms which are: events, processes, objects, and agent-based modeling paradigm, refer to [11, 12]. The 2D diagram of the trailer camper manufacturing assembly plan is shown in Figure 1 and the view of simulation model created in SIMIO software is shown in Figure 2.

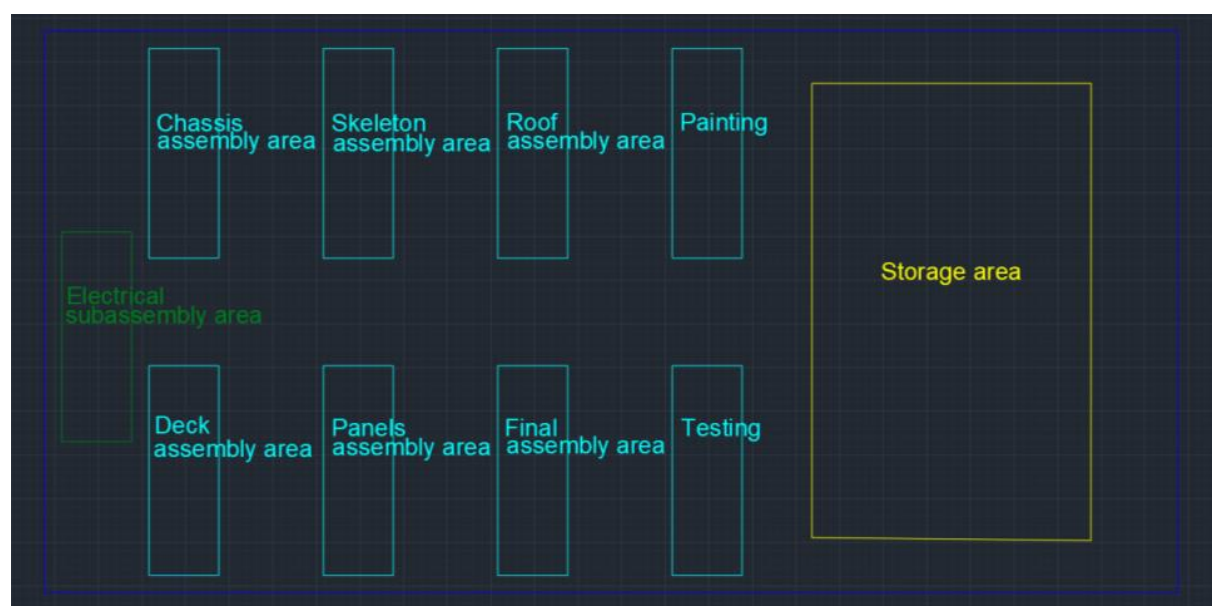

Figure 1. Diagram of the trailer camper manufacturing assembly plant

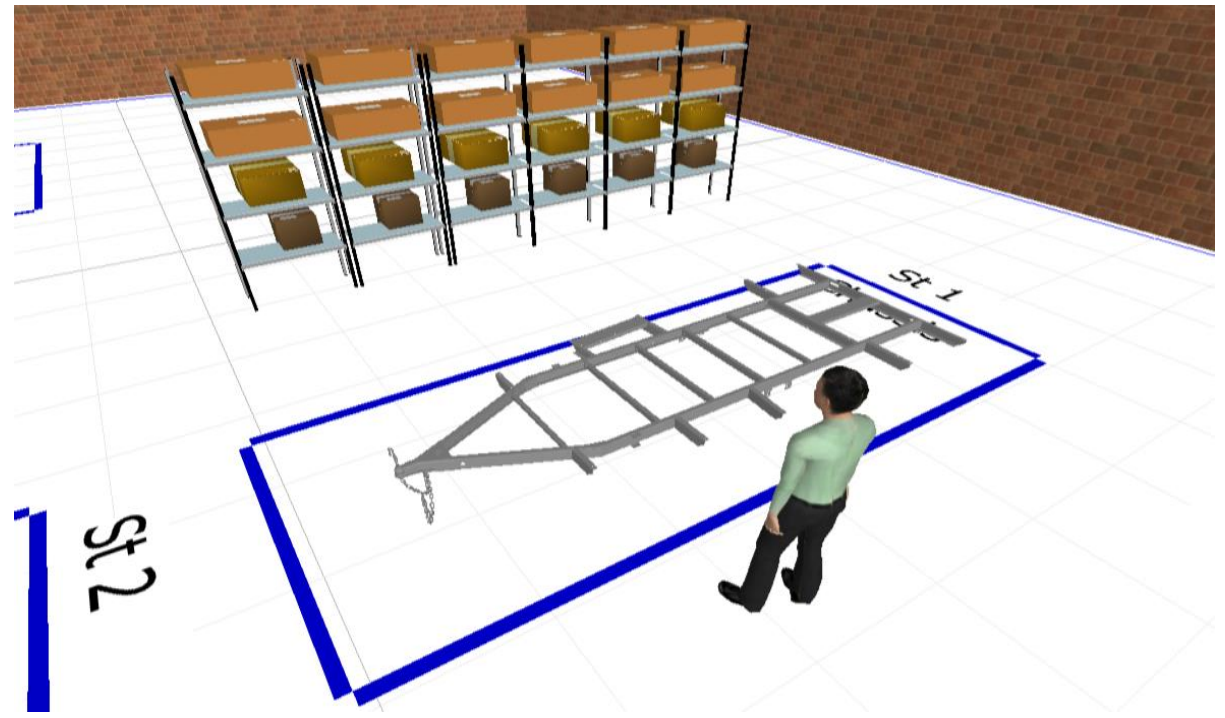

Figure 2. View of the simulation model created in SIMIO simulation software 


\section{VIRTUAL REALITY MODEL DEVELOPMENT:}

This section describes the implementation of virtual reality (VR) for classroom activities. Students were divided into groups and assigned different tasks to complete the project. The objective of the project was to develop a virtual environment to show the assembly of different components of a cell phone. Figure 3 demonstrate the broad picture of the VR model development.

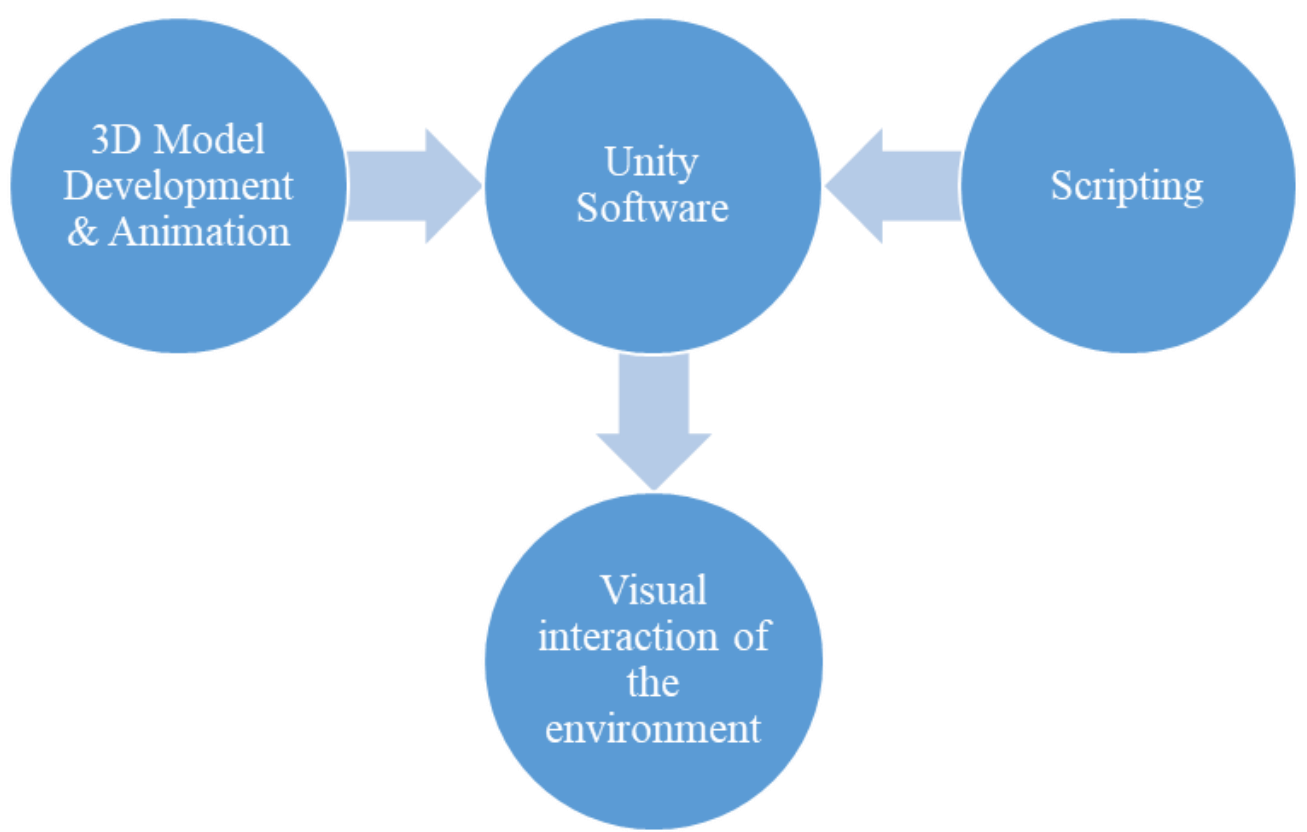

Figure 3. Schematic diagram of virtual reality model development

The first step of developing a virtual reality model is to work with 3D modelling. Students first identified the different components of a cell phone namely the motherboard, screen, body, camera, battery, case, back cover, and different buttons. Later, they design these components using the Maya 3D modelling software and import them into.$f b x$ format. FBX format is used to provide interoperability between digital content creation applications. Once the 3D model of the different components is built, they are imported into the Unity software

Unity is game engine, which is being extended to support different cross-platforms like android, iOS, windows etc. Also, it is a $2 \mathrm{D} / 3 \mathrm{D}$ engine and framework that provides a system for designing game or app scenes for 2D and 3D. It not only allows to interact via code, but also through visual components as it exports them to every platform. This framework, supports different file format related to 3D Model and Audio formats, can write code to interact with the model and imports animations for use with an advanced animation system. $\mathrm{C \#}$ is the only scripting language supported by Unity. Likewise, it can be created within unity. The purpose of writing code is to make the 3D model to perform some action based on the given function within the class of the script. Various actions can be done by retrieving the behaviors or component values of the 3D model via script. In this framework, a script can also be added as component to a 3D object. Thus, a user can set a behavior to an object. This script is performed in run time, whenever that specific object is called or by other script. For an instance, to change the position of the 3D object via script, the position of the 3D object is changed from current position value to new position value by retrieving transform component from that specific object. This action is performed once the application starts, because the script is added to that specific object as a component. 
In this project, students developed and implemented a 3D model of a cell phone to show the interaction among different components in a virtual environment. The purpose if this project is to demonstrate the assembly and disassembly process alongside the process time analysis and other operational analysis through the clear visualization in the virtual environment. Here, the supported device has a $4 \mathrm{~K}$ resolution, which aids to improve the quality of the $3 \mathrm{D}$ model to visualize in a virtual environment. Unity game engine extended support to build for cross-platform where it can be deployed to the virtual headset. This framework provides built-in support for Extended Reality (XR). Extended Reality package includes three different types of application, Augmented Reality, Virtual Reality, and Mixed Reality. Implemented package aids to make the VR controller utilize in the project. To make the interaction between the controller and the $3 \mathrm{D}$ object, manual scripts are written. In a script, utilizing each 3D model components (Unity Features) of mesh collider, mesh renderer, and box collider, interaction to assemble and disassemble are made possible. Usage of the manual script to collide the VR controller and 3D model in Virtual world aids to achieve assemble and disassemble processes during run time. The interaction of cell phone assembly in VR environment is show in Figure 4.

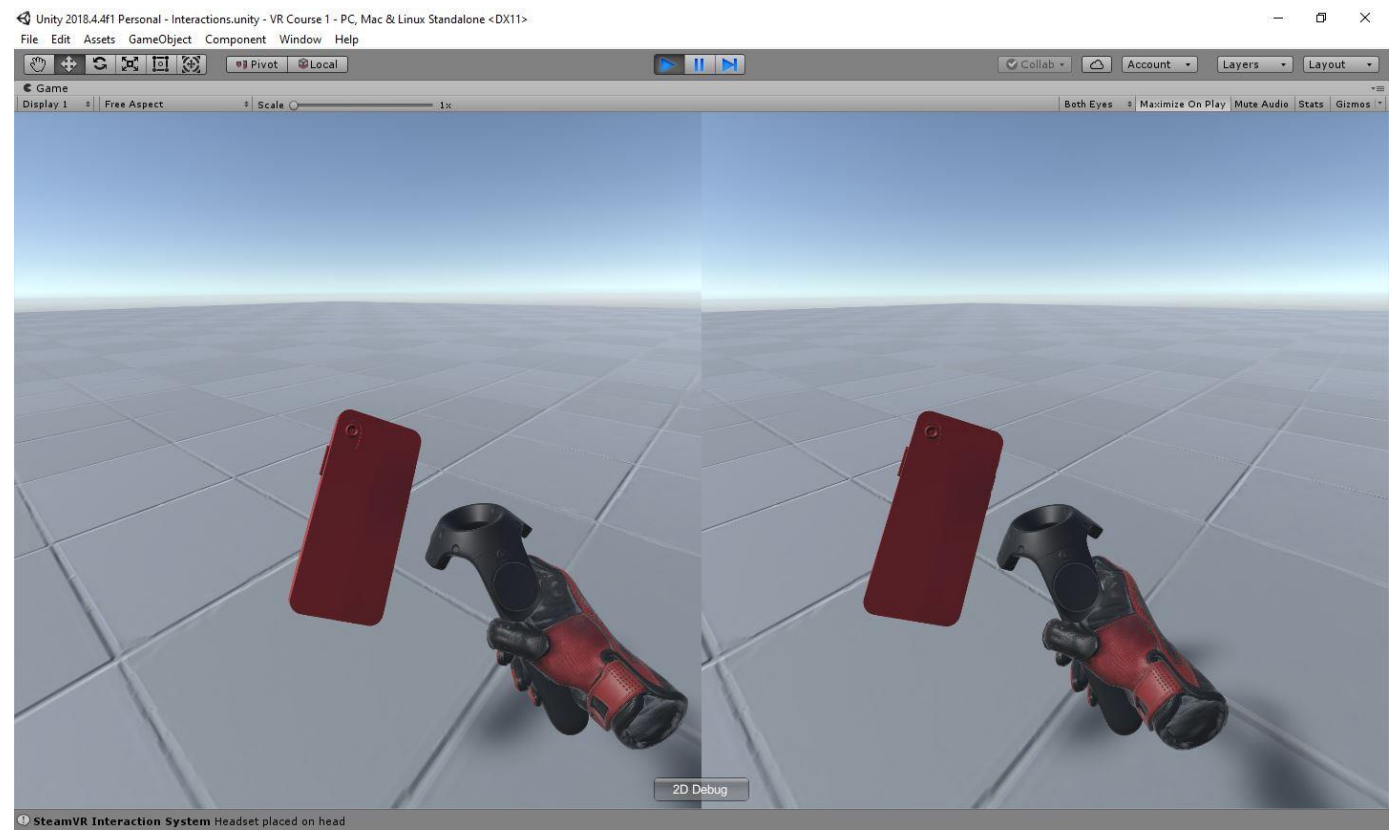

Figure 4. Interaction of cell phone assembly in VR environment (Unity platform)

\section{STUDENT ASSESSMENT}

The objective of performing the student assessment is to know the learning outcome of embedding the simulation-based classroom activates among the students. To attain this objective, we divide the students into two groups. In the first half of the semester, the students performed the project on trailer camper manufacturing assembly plant. In this case, Group 1 performed the project using SIMIO software, whereas group 2 accomplished their project using paper-based activity. In the last half of the project, the students took another project on cell phone assembly. This time, group 1 accomplished their project using paper-based activity, whereas group 2 completed that using virtual reality technology. After completing these two projects, we assessed the students' knowledge and understanding on the subject matter. The students were asked to submit a group report, a quiz and a survey, which were used to do the overall rating for the students. The report 
and quiz were designed to access the knowledge on assembly design, product decomposition, dependency analysis, time analysis, and operational analysis. Whereas the survey was designed to the understand the feelings about the classroom learning experience and students' motivation to accomplish their project. The survey was anonymous, which made to students comfortable to share their opinion about the classroom activities. For doing the rating, we used five points numbering scale, where 1 indicates the least understanding and 5 indicate the best understanding. The detailed assessment result is shown in Table 1. Here, first column of the table indicates the three-fold benefits mentioned in the abstract. The rating for assembly line design, product decomposition, dependency analysis, process time analysis, and operation analysis reflects the students' learning outcomes to evaluate the design and analyze the operational performance of manufacturing systems. The other two indicator indicates the students' feelings on the classroom activities and their motivation on learning.

Table 1. Assessment result of the computer simulation project

\begin{tabular}{|c|c|c|c|}
\hline & Student assessment & Group1 & Group2 \\
\hline & $\begin{array}{c}\text { Project } 1 \text { (trailer camper manufacturing } \\
\text { assembly plant) }\end{array}$ & $\begin{array}{c}\text { Computer } \\
\text { simulation-based } \\
\text { activity }\end{array}$ & $\begin{array}{l}\text { Paper based } \\
\text { activity }\end{array}$ \\
\hline 1 & Assembly line design & 5 & 5 \\
\hline 1 & Dependency analysis & 4 & 4 \\
\hline 1 & Process time analysis & 4 & 3 \\
\hline 1 & Operation analysis & 4 & 3 \\
\hline 2 & Students' feelings on learning process & 5 & 4 \\
\hline \multirow[t]{3}{*}{3} & Students' motivation & 5 & 3 \\
\hline & Overall rating & 4.5 & 3.67 \\
\hline & $\begin{array}{c}\text { Project } 2 \\
\text { (Cell phone assembly) }\end{array}$ & $\begin{array}{l}\text { Paper based } \\
\text { activity }\end{array}$ & $\begin{array}{l}\text { Computer } \\
\text { simulation } \\
(\text { VR) }\end{array}$ \\
\hline 1 & Product decomposition & 5 & 5 \\
\hline 1 & Dependency analysis & 4 & 4 \\
\hline 1 & Process time analysis & 3 & 4 \\
\hline 1 & Operation analysis & 3 & 5 \\
\hline 2 & Students' feelings on learning process & 4 & 5 \\
\hline \multirow[t]{2}{*}{3} & Students' motivation & 3 & 5 \\
\hline & Overall rating & 3.67 & 4.67 \\
\hline
\end{tabular}

From the assessment table, it is observed that the student group who perform their project on the computer simulation, has the better understanding on their subject matter. Note that, the students submitted their report and quiz in group and assessed comprehensively. The survey was conducted individually. Regarding the table, it is clear that both of the student group hold the similar understanding for designing the assembly line and analyzing the dependency. This is due the fact that, the knowledge on assembly line design and dependency analysis mostly depends on the theoretical knowledge rather than the activity using computer simulation. Due to the same reason, we see that the student group has the analogous understanding on the product decomposition for the second project. However, referring to the process time analysis and operation analysis, the 
student group who accomplished their project using the computer simulation possesses have outstanding knowledge on the corresponding matter. This trend is observed for the both projects. Ideally, in computer simulation, there is more scope to play with different variables, parameters and situation, which is not possible to experience in paper-based project activity. Thus, the difference comes in understanding for process time analysis and operation analysis. Notice that, in project two, group 2 possesses excellent understanding for operation analysis in comparison of group 1. As it mentioned earlier that, virtual reality creates an environment where the user can interact with the components as like a real world. This gives the better understanding on acquiring concepts on working principle and operation of any system, which reflects in the student assessment table. Comprehensively, it is observed that, incorporating the computer simulation provides the better experience in students' learning process. Apparently, the students who accomplished their project using the computer simulation feels very positive in learning process and motivation in classroom activities.

\section{CONCLUSION}

Recently, computer simulation has drawn significant attention in the field of manufacturing due to its promising applications. In near future, most of the industrial activity will be followed by the outcome of the computer simulation. Hence, student learning and understanding should go in parallel of the future demand. However, it is not feasible to set up a physical industrial scale manufacturing environment in classroom setting. So, computer simulation is the only way that can give the environment of industrial setting among the student sitting in the classroom. From this paper it is clear that, this approach is very effective in the students' learning process. However, the result of this paper reflects the outcome of a single course in Fall 2019 semester, where only 12 students were enrolled and accomplished two different projects. To understand the broader impact of embedding the simulation-based activity we need more case study with different projects and large number of students. In future, we will conduct more projects in the upcoming semester to assert the effectiveness of this approach.

\section{REFERENCES}

[1] R. Graham, "The global state of the art in engineering education," Massachusetts Institute of Technology (MIT), Massachusetts, 2018.

[2] K. Zhou, T. Liu and L. Zhou, "Industry 4.0: Towards future industrial opportunities and challenges," in IEEE, 12th International conference on fuzzy systems and knowledge discovery (FSKD)., 2015.

[3] I. Jawahir, F. Badurdeen and K. Rouch, "Innovation in Sustainable Manufacturing Education," in 11th Global Conference on Sustainable Manufacturing, Berlin-Germany, 2013.

[4] C. E. S. da Silva, E. G. Salgado, C. H. P. Mello, E. d. S. Oliveria and F. Leal, "Integration of computer simulation in design for manufacturing and assembly," Internation Journal of Production Research, vol. 52, no. 10, pp. 2851-2866, 2014.

[5] J. O'Kane, "Simulation as an enabler for organizational excellence," Measuring business excellence, vol. 7, no. 4, pp. 12-19, 2003.

[6] S. Makris, L. Rentzos and G. Pintzos, "Virtual Reality in Manufacturing," in CIRP Encyclopedia of Production Engineering, Springer, Berlin, Heidelberg, 2018. 
[7] C. M. Network, "CMTC Manufacturing Blog," California Manufacturing Technology Consulting, 2020. [Online]. Available: https://www.cmtc.com/blog/how-virtual-reality-ischanging-the-manufacturing-game.

[8] L. P. Berg and J. M. Vance, "Industry use of virtual reality in product design and manufacturing: a survey," Virtual Reality, vol. 21, no. 1, pp. 1-17, 2017.

[9] J. S. Simth, T. S. David and W. D. Kelton, Simio and simulation: modeling, analysis, applications., Simio LLC, 2018.

[10] G. S. Fishman, Principles of discreate event simulaiton. [book review], 1978.

[11] A. Renteria-Marquez, "Risk mitigation in the supply chain by multiple phase-in and phaseout components using Simio-simulation," in M.S. thesis, The University of Texas at El Paso, 2017.

[12] I.-A. Renteria-Marquez, "A Leveling Production Strategy to Automated Assembly Using Queuing Systems Software Through Simio Simulation," in M.S thesis, The University of Texas at El Paso, 2018. 